\title{
Pattern of admissions into the newborn unit of university of Uyo Teaching Hospital, Nigeria
}

\author{
Akpanl M.U. ${ }^{1}$, Nyong E.E. ${ }^{2}$ \\ ${ }^{1}$ Mkpouto U. Akpan., ${ }^{2}$ Eno E. Nyong, both authors are affiliated with Department of Paediatrics, University of \\ Uyo Teaching Hospital, Uyo, Akwa-Ibom State, Nigeria.
}

Address for Correspondence: Dr Mkpouto Udeme Akpan, Department of Paediatrics, University of Uyo Teaching Hospital, Uyo, Akwa Ibom State, Nigeria. E- mail: mkpoutoakpan@yahoo.com

\begin{abstract}
Background: Neonatal conditions have been noted to contribute significantly to under-five mortality rate. Knowledge of its pattern in our environment will help in planning for improved health care delivery. Aim: To determine the morbidity and mortality patterns of patients admitted into the neonatal unit of the University of Uyo Teaching Hospital, Nigeria. Methods: A retrospective analysis of the medical records of patients admitted into the neonatal unit of the University of Uyo Teaching Hospital over a period of twelve months from $1^{\text {st }}$ of January, 2011 to $31^{\text {st }}$ of December, 2011 was carried out. Information extracted from the records included age at presentation, gender, duration of hospitalisation, main diagnosis, and outcome. Results: A total of 997 neonates were admitted during the period of review. The male to female ratio was 1.1:1 in favour of the males (529:468). Of these, the commonest diagnoses were: neonatal sepsis $253(25.38 \%)$, prematurity $188(18.86 \%)$, neonatal jaundice 181(18.15\%) and birth asphyxia 137(13.74\%). Mean duration of admission was9 days. The overall mortality rate was $12.9 \%$ with a male to female death ratio of $1.3: 1$. Gender-related fatality rate was higher in males than females at $13.8 \%$ and $12.0 \%$ respectively. Majority $(80.6 \%)$ of the deaths occur among the out-born while (43.4\%) occur within 24 hours of admission. Conclusion: Most of the neonatal deaths were from preventable diseases. Good antenatal care is advocated for all pregnant women. This will help in screening, identification and timely referral of high risk pregnant women from primary health facilities to secondary and tertiary health facilities.
\end{abstract}

Keywords: Morbidity, Mortality, University of Uyo teaching hospital, Neonates

\section{Introduction}

The neonatal period is the most fragile and vulnerable period of life due to the large number of problems and diseases which the newborn is likely to face. Neonatal morbidity and mortality contributes significantly to under- five morbidity and mortality in Sub-Saharan African, accounting for $40 \%$ of the under- five mortality rate world wide [1]. Approximately three quarters of neonatal deaths occur in the first week of life with more than one quarter occurring within the first twenty-four hours [2].

This is so because the first week of life is the transitional period from intrauterine to extra-uterine

Manuscript received: $8^{\text {th }}$ September 2017

Reviewed: $17^{\text {th }}$ September 2017

Author Corrected: $25^{\text {th }}$ September 2017

Accepted for Publication: 30 ${ }^{\text {th }}$ September 2017 life. Causes of neonatal deaths vary greatly from country to country. Worldwide, the common causes of neonatal death include infections (36\%), prematurity (28\%), and birth asphyxia (23\%) [3]. In Nigeria, the common causes and their proportions vary depending on the geographical location but birth asphyxia, prematurity and neonatal sepsis have been reported as the common causes [4-8]. Majority of these causes are preventable. Poor maternal health, adverse social conditions, inadequate care during pregnancy, delivery and the immediate postpartum period coupled with poor infrastructure of the primary health facilities and cultural beliefs are some of the contributory factors. Knowledge of the pattern of admissions and its outcome will help policymakers to plan preventive measures that will help to reduce 
mortality and morbidity during this vulnerable period of life. This study sought to know the pattern of morbidity and mortality as there is no known study in our environment.

\section{Materials and Methods}

Study design and setting:-This retrospective study was conducted in the newborn unit of the University of Uyo Teaching Hospital, Uyo. The newborn unit of this hospital is made up of two subunits; the Special Care Babies Unit (SCBU) and the Sick Babies Unit (SBU). SCBU admits all inborn babies whose mothers had antenatal care either in University of Uyo Teaching Hospital (UUTH) or any other government registered health facility and delivered in UUTH while SBU caters for all out-born and also interfered cases that later delivered in UUTH.

The Newborn Unit accepts all babies between the ages of zero and twenty-eight days. The unit is well equipped with cots, radiant warmers, incubators and phototherapy machines. It also has fullcomplement of staff ranging from neonatal nurses, registered nurses/ midwives, Resident doctors and two Consultant Neonatologists.

The preterm babies are usually nursed in incubators and the very sick newborns, extremely or very low birth weight babies are cared for with the use of radiant warmers, phototherapy units and nasogastric tube feeding. Mothers' milk is used to feed most of the babies and formula feeds are only used when it is not possible to get mothers' milk. Oxygen is also given to babies who are in need.

Weighing scales and infantometer are used to measure respectively while measuring tape is used to measure the weight and length of these neonates the occipito-frontal circumference.

Babies with birthweight of less than 2500grams are considered as low birth weight, less than
1500 grams as very low birth weight while less than 1000 grams, extreme low birth weight [9].

Using the gestational age, a preterm delivery was considered if the baby was delivered before thirtyseven completed weeks while post term delivery was considered if the baby was delivered after forty-two completed weeks.

UUTH is one of the two tertiary health facility in Akwa-Ibom state, the second being the Ibom international specialist hospital. It serves as a referral centre to people within and outside AkwaIbom State. It is located about six kilometres from the heart of Uyo, the capital of Akwa-Ibom State.

Inclusion criteria- All babies aged 0-28days admitted into the newborn unit from $1^{\text {st }}$ of January, 2011 to $31^{\text {st }}$ of December, 2011.

Exclusion criteria- Babies older than 28days and those not admitted into the newborn unit.

Participants- Babies who were admitted into the newborn unit.

Variables- Age (days) at admission, gender, main diagnosis, duration of hospitalisation, outcome

Data source- Case notes of all patients admitted into the Newborn Unit during the study period were retrieved. Information extracted included the following: age at presentation, gender, diagnosis, age at discharge and outcome of admission.

Bias- None was anticipated nor observed in the study.

Study size-A total of nine hundred and ninetyseven neonates were studied.

Statistical methods- The data was analysed using SPSS Package 20. Frequencies were drawn using tables, compared using Chi-square; and means using the student t-test. p-value of $<0.05$ was regarded as significant.

\section{Results}

A total of nine hundred and ninety-seven neonates were admitted during the period under review of which 521 were admitted into SBU and 476 into SCBU. Five hundred and twenty-nine (53.1\%) were males and 468 $(46.9 \%)$ were females giving a male to female ratio of 1.1:1. Four hundred and seventy-six were inborn while 521 were out-born. Eight hundred and thirty neonates were admitted before the age of seven days and 167 were admitted after the age of 7days. A greater number of the neonates admitted into SBU were older than 7days old while majority of the admissions in SCBU were less than 7days of age and this was statistically significant with $\mathrm{p}$-value $<0.01$. This is shown in table 1 
Table- 1: Shows the age of the neonates at presentation in the hospital.

\begin{tabular}{|c|c|c|c|c|c|}
\hline & Ward & Admitted & & & \\
\hline Age at presentation & SBU (521) & SCBU (476) & Total (997) & $X^{2}$ & p-value \\
\hline$<$ 7days & 372 & 458 & 830 & & $<0.01$ \\
\hline 7days or more & 149 & 18 & 167 & 109.86 & \\
\hline Total & $\mathbf{5 2 1}$ & $\mathbf{4 7 6}$ & $\mathbf{9 9 7}$ & & \\
\hline
\end{tabular}

Diagnosis at presentation: Table 2 shows the pattern of admissions in the newborn unit. The four commonest diagnoses were: neonatal sepsis $253(25.38 \%)$, prematurity $188(18.86 \%)$, neonatal jaundice $181(18.15 \%)$ and birth asphyxia 137(13.74\%). Other disease conditions were: HIV exposed 8(0.8\%), hypoglycaemia 4(0.4\%), infant of diabetic mother 11(1.1\%), infant of rhesus negative mother 3(0.3\%), intestinal obstruction $8(0.8 \%)$, intra-uterine growth restriction $2(0.2 \%)$, local infection $17(1.7 \%)$, low birth weight $4(0.4 \%)$, macrosomic baby 32 (3.21\%), meconium aspiration syndrome 18(0.18\%), neonatal meningitis $14(1.4 \%)$, neonatal seizure $7(0.7 \%)$, neonatal tetanus $11(1.1 \%)$, pneumonia $13(1.3 \%)$, post-date baby $2(0.2 \%)$, respiratory distress syndrome 3(0.3\%), severe anaemia $1(0.1 \%)$, spinal bifida $8(0.8 \%)$, transient tachypnoea of newborn $5(0.5 \%)$. Neonatal sepsis was noted as the commonest presentation among out-born as well as inborn neonates.

Table- 2: Shows the pattern of admission into newborn unit.

\begin{tabular}{|c|c|c|c|c|}
\hline Disease condition & SBU & SCBU & Total & Percentage \\
\hline Malaria & 3 & 8 & 11 & 0.11 \\
\hline Birth asphyxia & 75 & 62 & 137 & 13.74 \\
\hline Birth trauma & 4 & 3 & 7 & 0.7 \\
\hline Congenital abnormality & 34 & 6 & 40 & 4.01 \\
\hline HIV exposed & 4 & 4 & 8 & 0.8 \\
\hline Infant of diabetic mother & - & 11 & 11 & 1.1 \\
\hline Intestinal obstruction & 8 & - & 8 & 0.8 \\
\hline Local infection(omphalitis) & 13 & 4 & 17 & 1.71 \\
\hline Macrosomic baby & - & 32 & 32 & 3.21 \\
\hline Meconium/liquor aspiration & 4 & 14 & 18 & 1.8 \\
\hline Neonatal meningitis & 14 & - & 14 & 1.4 \\
\hline Neonatal jaundice & 68 & 113 & 181 & 18.15 \\
\hline Neonatal seizure & 6 & 1 & 7 & 0.7 \\
\hline Neonatal tetanus & 11 & - & 11 & 1.1 \\
\hline pneumonia & 12 & 1 & 13 & 1.3 \\
\hline prematurity & 108 & 80 & 188 & 18.86 \\
\hline Neonatal sepsis & 130 & 123 & 253 & 25.38 \\
\hline Spinal bifida & 8 & - & 8 & 0.8 \\
\hline Others & 17 & 16 & 33 & 3.31 \\
\hline Total & 521 & 476 & 997 & 100 \\
\hline
\end{tabular}

Duration of hospitalization: Period of hospitalization ranged from one hour to 62days with a mean duration of 9days. Eighty-six out of 134 patients that were hospitalized for less than 24hours were admitted in SBU and 48 in SCBU. There were significantly more admissions in SBU than SCBU that spent $<24$ hours in hospital $(\mathrm{p}=0.003)$. This is shown in table 3 .

Table- 3: Shows the duration of hospital in relationship to the ward the patient was admitted.

\begin{tabular}{|c|c|c|c|c|c|}
\hline & Ward & Admitted & & & \\
\hline Duration of admission & SBU & SCBU & Total & $\boldsymbol{X}^{2}$ & p-value \\
\hline$<24$ hours & 86 & 48 & 134 & & 0.003 \\
\hline$>24$ hours & 435 & 428 & 883 & 8.82 & \\
\hline Total & $\mathbf{5 2 1}$ & $\mathbf{4 7 6}$ & $\mathbf{9 9 7}$ & & \\
\hline
\end{tabular}


Outcome: Of the total number of admissions, 129 patients died. The death rate was higher among the out-born than the inborn. Also, a higher number of out-born left the hospital against medical advice. A significantly higher number of inborn recovered and were discharged home $(\mathrm{p}=<0.01)$. This is shown in table 4 .

Table-4: Shows the association between care outcome of admission and ward of admission.

\begin{tabular}{|c|c|c|c|c|c|}
\hline & Ward & Admitted & & & \\
\hline Outcome & SBU & SCBU & Total & $\boldsymbol{X}^{2}$ & p-value \\
\hline Discharged & 350 & 441 & 791 & & $<0.01$ \\
\hline Died & 104 & 25 & 129 & 99.22 & \\
\hline Left against medical advice & 67 & 10 & 77 & & \\
\hline Total & $\mathbf{5 2 1}$ & $\mathbf{4 7 6}$ & $\mathbf{9 9 7}$ & & \\
\hline
\end{tabular}

Out of 129 patients that died, $56(43.4 \%)$ died within 24 hours of admission and 73 (56.6\%) died after 24 hours of admission. Among the patients that left against medical advice, 11 (14.28\%) left within 24 hours of admission while $66(85.72 \%)$ left after 24 hours of admission. There was significantly more deaths among those hospitalized for $<24$ hours than among those hospitalized for $>24$ hours ( $p=0.003$ ). This is shown in table 5 .

Table- 5: Shows the association between care outcome and duration of hospitalization

\begin{tabular}{|c|c|c|c|c|c|}
\hline & Duration of & Admission & & & \\
\hline Outcome & $<24 h o u r s$ & $\mathbf{2 4 h o u r s}$ & Total & $\boldsymbol{X}^{\mathbf{2}}$ & p-value \\
\hline Discharged & 67 & 724 & 791 & & $<0.01$ \\
\hline Died & 56 & 73 & 129 & 716.44 & \\
\hline $\begin{array}{c}\text { Left against } \\
\text { medical advice }\end{array}$ & 11 & 66 & 77 & & \\
\hline Total & 134 & 863 & 997 & & \\
\hline
\end{tabular}

Table- 6 shows the different causes of death among the 129 neonates that died. The four commonest causes of death were prematurity 44, birth asphyxia 26, neonatal sepsis 22 and congenital abnormality 12.

Table- 6: Shows the causes of death.

\begin{tabular}{|c|c|c|}
\hline Cause of death & N (129) & Percentage \\
\hline Birth asphyxia & 26 & 20.16 \\
\hline Congenital abnormality & 12 & 9.3 \\
\hline Intestinal obstruction & 1 & 1.55 \\
\hline Local infection(omphalitis) & 2 & 0.76 \\
\hline Low birth weight & 1 & 0.76 \\
\hline Meconium aspiration & 1 & 1.55 \\
\hline Neonatal meningitis & 2 & 3.88 \\
\hline Neonatal jaundice & 5 & 0.76 \\
\hline Neonatal seizure & 1 & 4.65 \\
\hline Neonatal tetanus & 6 & 1.55 \\
\hline Pneumonia & 2 & 34.11 \\
\hline Prematurity & 44 & 0.76 \\
\hline Respiratory distress syndrome & 1 & 17.05 \\
\hline Neonatal sepsis & 22 & 2.33 \\
\hline Spinal bifida & 3 & $\mathbf{1 0 0}$ \\
\hline Total & $\mathbf{1 2 9}$ & \\
\hline
\end{tabular}




\section{Discussion}

This is the first clinical audit of admissions into the neonatal unit of this hospital since it was established in 1997. The male preponderance observed in this study is consistent with other studies within and outside our environment [4, 1011]. This indicates that male newborns are more vulnerable during the neonatal period and this agrees with the well described biological survival of females in the neonatal period [12]. It could also be as a reflection of male child preference which is seen in some culture [13]. In our traditional community, male children are preferred and so are more valued and catered for than the female. It therefore means that sick male children are taken to the best health facilities such as tertiary hospitals so as to increase their chances of survival. This observation is in contrast with findings from a study in Karachi, India where female neonates outnumbered the males [14].

The finding that majority of the patients were admitted within the first seven days of life has been reported in other studies [4]. This is because the first week of life is a transitional period from intrauterine to extra-uterine life and is considered to be the most fragile and vulnerable period.

Out-born babies were more in number than the inborn $(52.3 \%$ and $47.7 \%$ respectively). This is comparable to 53.54 and 46.46 reported by Rakholia et al [11] in India and 61.8\% and 38.2\% reported by Orimadegun et al in Southwest Nigeria [15].

Neonatal sepsis which was observed as the commonest cause of neonatal admission is similar to what is obtained worldwide. Neonatal sepsis was responsible for $25.38 \%$ of neonatal admissions. This was lower than $37.1 \%$ obtained by Torma et al [6] in Northern Nigeria. Ugwu [16] in her study in a tertiary care institution in South-south Nigeria reported a rate of $35.3 \%$.

This could be as a result of the fact that all children with presumed sepsis were included in this group. In contrast, Ekwochi et al[4] in their study in South-eastern reported that neonatal sepsis was the third commonest cause of neonatal admission. The commonest cause of neonatal admission in their study was peri-natal asphyxia. The other common causes of neonatal admissions in the present study were prematurity, neonatal jaundice and birth asphyxia and these were similar to reports by other authors in Nigeria [6,7].

Mortality rate of $12.9 \%$ was obtained in the present study. This is lower than $20.3 \%$ reported by Ugwu [16] and Omoigberale et al [17] from two different tertiary health care centres in Southern Nigeria.

More males died in the present study with a male to female ratio of 1.3:1. Gender-related fatality rate was also higher in males than females at $13.8 \%$ and $11.9 \%$ respectively. This is similar to report from other centres in Southern Nigeria[16]. The finding supports the fact that male newborns are more vulnerable during the neonatal period. The commonest causes of death were prematurity, birth asphyxia and neonatal sepsis which are similar to reports by other studies in Nigeria [4-7,16-17].

\section{Conclusion}

This study adds to the existing knowledge that most of the neonatal deaths were from preventable diseases. Good ante natal care is advocated for all pregnant women. This will help in screening, identification and timely referral of high risk pregnant women from primary health facilities to secondary and tertiary health facilities.

Authors Contributions- MUA conceived and designed the study, EEN collected, analysed and interpreted the data, while MUA drafted the article as well as carried out a critical revision of the article. Final approval of the version to be published was by MUA and EEN.

\section{Funding: Nil, Conflict of interest: None Permission of IRB: Yes}

\section{References}

1. Lerberghe WV, Manuel A, Matthews Z, Wolfheim CI. Make every mother and child count. World Health Report, 2005. Genevas: World Health Organization, WHO Press; 2005. P9.

2. Lawn JE, Cousens S, Zupan J. Lancet Neonatal Survival Steering Team. 4 million neonatal deaths: when? Where? Why? Lancet. 2005 Mar 5-11; 365 (9462) :891-900. 
3. Lawn JE, Cousens SN, Wilczynska K. Estimating the causes of four million neonatal deaths in the year2000: statistical annex. In: The world health report 2005. Geneva: WHO; 2005.

4. Ekwochi U, Ndu IK, Nwokoye IC, Ezenwosu OU, Amadi OF, Osuorah D ${ }^{1}$. Pattern of morbidity and mortality of newborns admitted into the sick and special care baby unit of Enugu State University Teaching Hospital, Enugu state. Niger J ClinPract. 2014 May-Jun;17(3):346-51. doi: 10. 4103 /1119-3077.130238.

5. Eke CB, Ezomike UO, Korie FC, Chukwudi N, Ukpabi IK. Pattern of neonatal mortality in a tertiary health facility in Umuahia, South East, Nigeria. Int J Trop Disease and Health. 2014; 4(2): 136-46. DOI-109734/IJDH/2014/4985.

6. Torma BO, Ige OO, AbokII, Onwuanaku C, Abah RO. Pattern of neonatal admissions and outcome in a tertiary institution in north central Nigeria. J Med Trop. 2013; 15(2): 121-5.

7. Okechukwu AA, Achonwa A. Morbidity and mortality patterns of admissions into the Special Care Baby Unit of University of Abuja Teaching Hospital, Gwagwalada, Nigeria. Niger J ClinPract. 2009 Dec;12(4):389-94.

8. Adebami OJ, Joel-Medewase AVI, Oyedeji OA, Oyedeji GA. A review of neonatal admissions in Osogbo, South-western Nigeria. Nig Hosp Pract. 2010; 5(3-4): http://dx.doi.org/10.4314/nhp.v5i3-4. 57848 .

9. Southgate WM, Pittard WB. Classification and physical examination of the newborn infant in: Klaus and Fanaroff, eds. Care of the high risk neonates, $5^{\text {th }}$ ed. Philadelphia. W. B. Saunders company; 2001: pp 100-29.

10. Eke EU, Modupe OO. Pattern of diseases and care outcomes of neonates admitted in Special Care
Baby Unit of University College Hospital, Ibadan, Nigeria from 2007 to 2011. IOSR J of Nursing and Health Sci. 2015;4(3): 62-71. DOI: 10. 9790/195904316271.

11. Rakholia R, Rawat V, Bano M, Singh G. Neonatal morbidity and mortality of sick newborns admitted in a teaching hospital of Uttarakhad. Chrismed J Health and Research.2014;1(4):228-34.

12. Salem M, Ali M, Anwer J, Babar MI, Rafi M, Mahamood $\mathrm{R}$ et al. Clinical audit of neonatal admissions in a tertiary care hospital. JSZMC 2011; 2(4): 231-35.

13. Doctor AV, Bairagi R, Findley SE, Helleringer S, Dahiru T. Northern Nigeria Maternal, Newborn and Child Health Programme: Selected analyses from population-based baseline survey. The open demography Journal 2011; 4: 11-21.

14. Aijaz N, Huda N, Kauzar S. Disease burden of NICU at a tertiary care hospital, Karachi. J Dow university of Health Sciences Karachi. 2012; (6)1: 32-5.

15. Orimadegun AE, Akinbami FO, Tongo OO, Okereke JO. Comparison of neonates born outside and inside hospitals in a children emergency unit, southwest of Nigeria. PediatrEmergCare. 2008 Jun; 24 (6):354-8.doi:10.1097/PEC.0b013e 318177a73c.

16. Ugwu GI. Pattern of morbidity and mortality in the newborn special care unit in a tertiary institution in the Niger Delta region of Nigeria: A prospective study. Glob Adv Res J Med Sci. 2012; 1: $133-8$.

17. Omoigberale AI, Sadoh WE, Nwaneri DU. A4year review of neonatal outcome at the University of Benin Teaching Hospital, Benin City. Niger J ClinPract. 2010; 13: 21-5.

\section{How to cite this article?}

Akpanl M.U, Nyong E.E. Pattern of admissions into the newborn unit of university of Uyo Teaching Hospital, Nigeria. Int J Med Res Rev 2017;5(09):851-856.doi:10.17511/ijmrr. 2017.i09.04. 